\title{
A Case of Ovarian Glomus Tumor and Literature Review
}

\author{
Wai Kheong Ryan Lee, b, Tracy Jiezhen Loh ${ }^{a}$, Yong Kuei Lima ${ }^{a}$, \\ Sung Hock Chew ${ }^{\mathrm{a}}$, Chit Chong Khong ${ }^{\mathrm{a}}$
}

\begin{abstract}
A 42-year-old Chinese female presented with postcoital bleeding and was incidentally found to have a complex mass in the left adnexal region on pelvic ultrasound. A laparoscopic left salpingo-oophorectomy performed showed an $8 \mathrm{~cm}$ cystic mass arising from the left ovary with an associated left fallopian tube hydrosalpinx. The mass was composed of epithelioid cells with a vague nested architecture which showed positive smooth muscle actin (SMA) immunohistochemical staining. Features were consistent with a glomus tumor, an extremely rare mesenchymal neoplasm arising in the ovary. Our case is hitherto the largest reported glomus cell tumor of the ovary measuring $8 \mathrm{~cm}$ to date. This tumor has uncertain malignant potential requiring close gynecological surveillance.
\end{abstract}

Keywords: Ovarian; Glomus

\section{Introduction}

Glomus tumors are rare mesenchymal neoplasms composed of cells which resemble the modified smooth muscle cells of a normal glomus body [1]. Typically, they occur in the distal extremities but rare tumors have been reported in internal organs including the female genital tract. Glomus tumors are exceedingly rare in the ovary. They have been reported in association with a teratoma [2] and arising de novo [3]. A microscopic glomus tumor ( $1 \mathrm{~mm}$ in size) has also been reported as an incidental finding by Maeda et al [4]. Thus far, these tumors have ranged in size from $1 \mathrm{~mm}$ to $4 \mathrm{~cm}$ in greatest dimension [5]. In this report, we described the largest ovarian glomus tumor measuring $8 \mathrm{~cm}$ in greatest dimension in a 42 year old female to date.

\section{Case Report}

A 42-year-old Chinese female presented with postcoital bleed-

Manuscript submitted December 25, 2017, accepted January 15, 2017

aDepartment of Obstetrics and Gynaecology, KK Women's and Children's Hospital, 100 Bukit Timah Road, Singapore 229899, Republic of Singapore

${ }^{b}$ Corresponding Author: Wai Kheong Ryan Lee, Department of Obstetrics and Gynecology, KK Women's and Children's Hospital, 100 Bukit Timah Road, Singapore 229899, Republic of Singapore. Email: rylee82@yahoo.com

doi: https://doi.org/10.14740/jmc2998w ing for several weeks to our hospital for evaluation. Abdominal and vaginal examination was unremarkable. Vaginal examination was normal and her most recent pap smear was normal. A pelvis ultrasound performed revealed a complex heterogeneous structure in the left adnexal region measuring $7.6 \times 6.2 \times$ $5.4 \mathrm{~cm}$ with areas of vascularity on Doppler (Fig. 1). Serum ovarian tumor markers showed a mildly elevated CA125 level at $41.8 \mathrm{U} / \mathrm{mL}(0.0-35.0 \mathrm{U} / \mathrm{mL})$ while CEA $1.6 \mu \mathrm{g} / \mathrm{L}(\leq 5.0$ $\mu \mathrm{g} / \mathrm{L})$, beta $\mathrm{hCG}<1.2(\mathrm{IU} / \mathrm{L})$ and AFP levels $2 \mu \mathrm{g} / \mathrm{L}(\leq 8 \mu \mathrm{g} / \mathrm{L})$ were not elevated.

Subsequently, the patient underwent a laparoscopic left salpingo-oophorectomy which revealed an $8 \mathrm{~cm}$ cystic mass arising from the left ovary with an associated small left fallopian tube hydrosalpinx (Fig. 2). The uterus was mildly enlarged with small fibroids and the contra lateral ovary and fallopian tube were otherwise normal.

The retrieved specimen was sent for histology where lesional cells showed positive immunohistochemical (IHC) staining for smooth muscle actin (SMA) with membrane accentuation (Fig. 3). Histology of the left ovary was consistent with a glomus tumor. Computed tomography (CT) scan of the abdomen and pelvis performed post operatively showed no evidence of metastatic disease.

\section{Discussion}

Glomus tumors rarely arise in the female genital tract and have been reported in the vulva $[6,7]$, clitoris $[7,8]$, vagina $[9,10]$, cervix [11] and ovaries [2-5]. Most tumors were incidental findings after hysterectomy for benign gynecological disease. Of four reported cases, three were incidental findings in patients who presented with cervical cancer, pelvic mass or co-existing endometrial cancer [2-4]. The fourth was initially thought to be a granulosa cell tumor [5].

Rarely do deep and large glomus tumors present with abdominal pain or abnormal vaginal bleeding unlike our case. Previous glomus tumors reported have ranged from $1 \mathrm{~mm}$ to 4 $\mathrm{cm}$ in size. To our knowledge, our case is hitherto the largest reported glomus cell tumor of the ovary measuring $8 \mathrm{~cm}$ to date.

Surgical resection remains the treatment in choice described in other viscera and diagnosed by histopathology [12, 13].The top differential diagnoses in this case based on hematoxylin and eosin ( $\mathrm{H}$ and $\mathrm{E}$ ) stained slides included cell surface epithelial carcinoma, sex-cord stromal tumor, neuroendocrine tumor, hepatoid carcinoma or metastatic gastrointestinal stromal tumor (GIST). Immunohistochemical staining using 


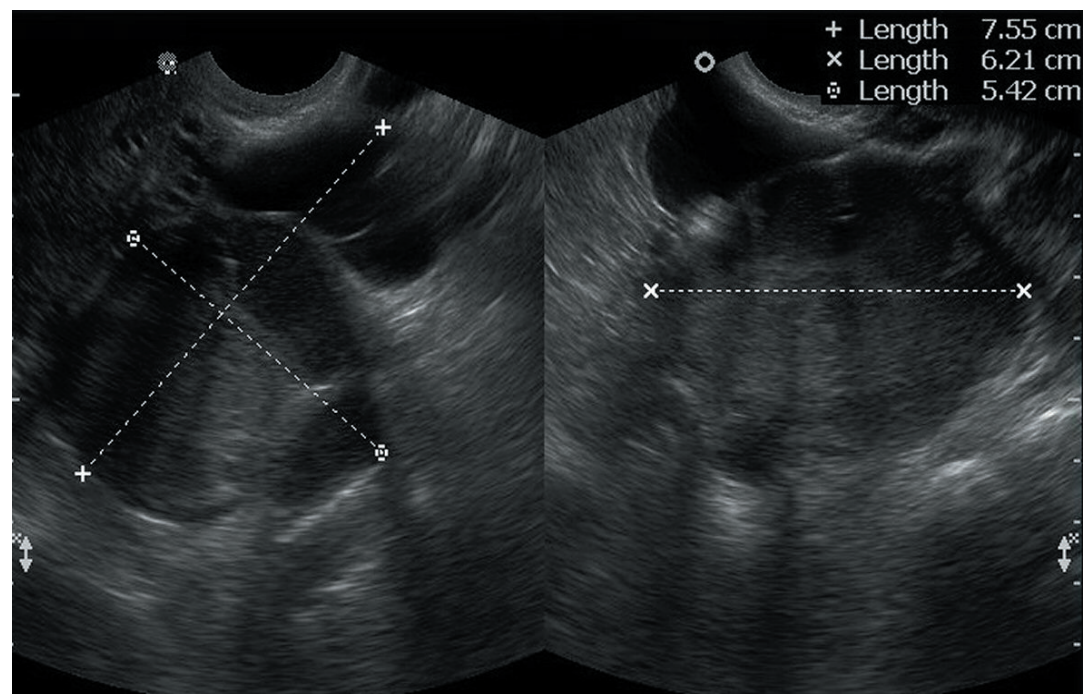

Figure 1. Pelvis ultrasound with left adnexal mass with echogenic solid component.

various markers such as pan-Cytokeratins alpha-inhibin, calretinin, synaptophysin, chromogranin, alpha fetoprotein, and c-Kit can be used to aid in the diagnosis.

The pathogenesis of ovarian glomus tumor remains unclear .The ovarian tumor was composed of epithelioid cells with a vague nested architecture which showed positive smooth muscle actin (SMA) immunohistochemical staining that was consistent with a glomus tumor, an extremely rare mesenchymal neoplasm arising in the ovary. On the contrary, the tumor was negative for pan-Cytokeratins AE 1/3 ruling out surface epithelial carcinoma while alpha-inhibin and calretinin were both negative ruling out a sex-cord stromal origin. Synaptophysin and chromogranin were negative for a well differentiated neuroendocrine tumor. Alpha fetoprotein (AFP) and c-Kit staining were negative for hepatoid carcinoma and metastatic gastrointestinal stromal tumor respectively.

Glomus tumors have been proposed to be classified into malignant, symplastic, glomangiomatosis or uncertain malig-

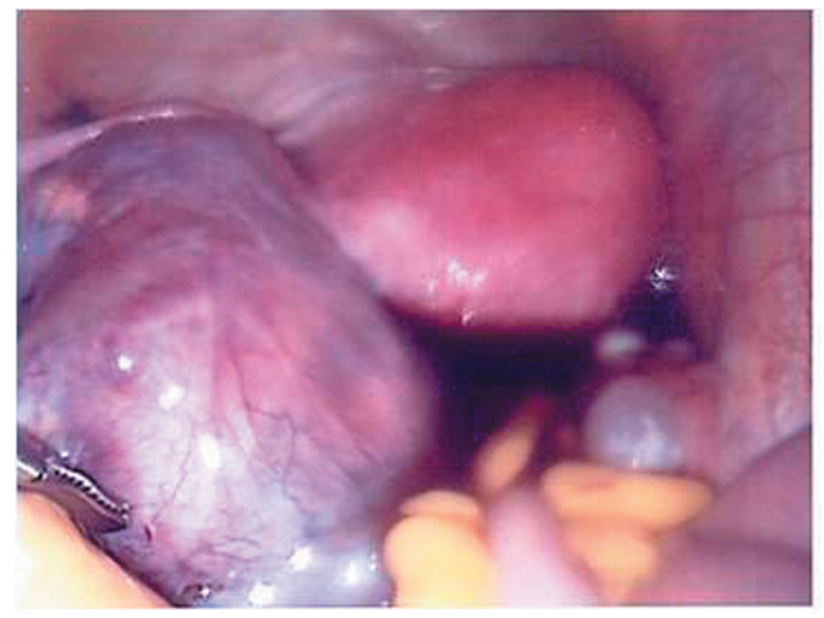

Figure 2. Diagnostic laparoscopy showing left $8 \mathrm{~cm}$ adnexal mass. nant potential which can aid in the diagnosis of rare neoplasms [14]. Clinical and pathological features of tumors include size, location, presence of mitotic figures and nuclear atypia. Malignant glomus tumors fulfill the criteria which include size greater than $2 \mathrm{~cm}$, or atypical mitotic figures or deep location or high nuclear grade [14]. However this classification was described in glomus tumors of other organs except the female genital tract due to its rarity.

In our case, no atypical mitotic figures or marked nuclear atypia was discerned which would justify a diagnosis of a malignant glomus tumor. However, in view of the large size of the lesion, we feel that the tumor has uncertain malignant potential that would require close surveillance with repeat imaging. Our patient had subsequent baseline postoperative CT scan which did not show any evidence of residual disease or metastasis. She is currently on close gynecological follow-up in our hospital 1 year later disease free.

In conclusion, a large glomus tumor of the ovary with typical immunohistochemical findings which although rare, should be considered in the differential diagnosis of ovarian lesions and followed up for its uncertain malignant poten-

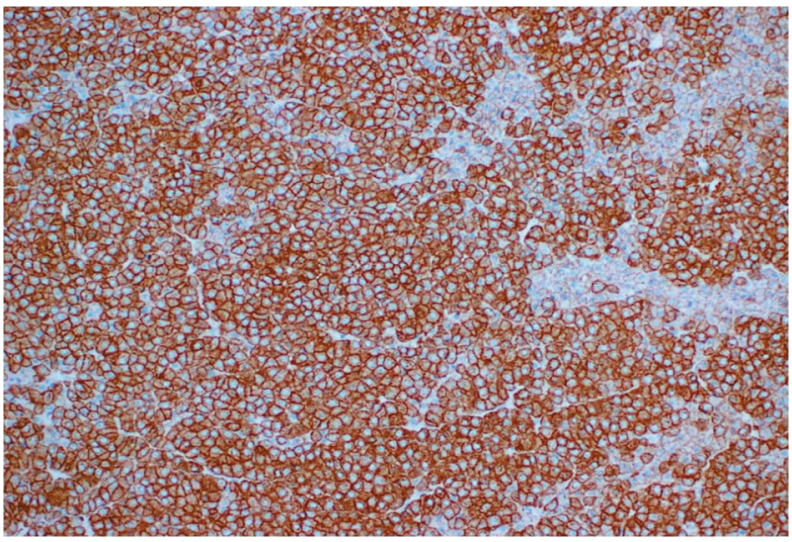

Figure 3. Smooth muscle actin immunohistochemical staining. 
tial.

\section{References}

1. Fletcher CDM, Bridge JA, Hogendoorn PCW, Mertens F, World Health Organization., International Agency for Research on Cancer. WHO classification of tumours of soft tissue and bone. Lyon: IARC, 2013.

2. Silver SA, Tavassoli FA. Glomus tumor arising in a mature teratoma of the ovary: report of a case simulating a metastasis from cervical squamous carcinoma. Arch Pathol Lab Med. 2000;124(9):1373-1375.

3. Gokten N, Peterdy G, Philpott T, Maluf HM. Glomus tumor of the ovary: report of a case with immunohistochemical and ultrastructural observations. Int J Gynecol Pathol. 2001;20(4):390-394.

4. Maeda D, Takazawa Y, Oda K, Nakagawa S, Fukayama M. Glomus tumor of the ovary: a case report. Int J Surg Pathol. 2010;18(6):557-560.

5. Slone SP, Moore GD, Parker LP, Rickard KA, NixdorfMiller AS. Glomus tumor of the ovary masquerading as granulosa cell tumor: case report. Int J Gynecol Pathol. 2010;29(1):24-26.

6. Katz VL, Askin FB, Bosch BD. Glomus tumor of the vulva: a case report. Obstet Gynecol. 1986;67(3 Suppl):43S-
$45 \mathrm{~S}$.

7. Sonobe H, Ro JY, Ramos M, Diaz I, Mackay B, Ordonez NG, Ayala AG. Glomus tumor of the female external genitalia: a report of two cases. Int J Gynecol Pathol. 1994;13(4):359-364.

8. Jagadha V, Srinivasan K, Panchacharam P. Glomus tumor of the clitoris. N Y State J Med. 1985;85(10):611.

9. Spitzer M, Molho L, Seltzer VL, Lipper S. Vaginal glomus tumor: case presentation and ultrastructural findings. Obstet Gynecol. 1985;66(3 Suppl):86S-88S.

10. Moldavsky M, Stayerman C, Turani H. Vaginal glomus tumor presented as a painless cystic mass. Gynecol Oncol. 1998;69:172-174.

11. Albores-Saavedra J, Gilcrease M. Glomus tumor of the uterine cervix. Int J Gynecol Pathol. 1999;18(1):69-72.

12. Vassiliou I, Tympa A, Theodosopoulos T, Dafnios N, Fragulidis G, Koureas A, Kairi E. Gastric glomus tumor: a case report. World J Surg Oncol. 2010;8:19.

13. Almaghrabi A, Almaghrabi N, Al-Maghrabi H. Glomangioma of the Kidney: A Rare Case of Glomus Tumor and Review of the Literature. Case Rep Pathol. 2017;2017:7423642.

14. Folpe AL, Fanburg-Smith JC, Miettinen M, Weiss SW. Atypical and malignant glomus tumors: analysis of 52 cases, with a proposal for the reclassification of glomus tumors. Am J Surg Pathol. 2001;25(1):1-12. 